\title{
OPTIMALISASI PENCAHAYAAN ALAMI DENGAN ALAT PEMBAYANG MATAHARI (SHADING DEVICE) PADA JENDELA RUANGAN KELAS
}

\author{
Yunita Ardianti Sabtalistia \\ Jurusan Teknik Arsitektur, Universitas Tarumanagara, Jakarta \\ yunita4architect@gmail.com
}

\begin{abstract}
ABSTRAK
Salah satu cara untuk menghemat energi listrik di dalam ruangan kelas adalah dengan memanfaatkan pencahayaan alami. Tingkat pencahayaan harus mencapai nilai rata-rata 350 lux agar siswa mampu melihat dengan jelas di dalam ruangan kelas. Salah satu ruangan kelas di SMAK Penabur Summarecon, Bekasi memanfaatkan pencahayaan alami yang diperoleh dari jendela yang berada pada sisi selatan dan utara bangunan. Model alat pembayang matahari (shading device) pada jendela yang digunakan di sekolah tersebut adalah model eggcrate yang membuat ruangan kelas menjadi tidak cukup terang sehingga masih membutuhkan lampu dari pagi sampai sore hari. Berdasarkan kondisi tersebut, maka tujuan penelitian adalah mengetahui model alat pembayang matahari yang paling optimal agar ruangan kelas cukup terang dan mempunyai tingkat keseragaman cahaya yang merata. Model shading device yang dieksperimen dengan menggunakan Ecotect v5.20 adalah eggcrate (kondisi eksisting), horizontal overhang, horizontal louver, vertical louver, dan light shelf. Hasil penelitian menunjukkan bahwa level pencahayaan rata-rata pada semua model tidak ada yang mencapai 350 Lux. Model shading device yang membuat ruangan paling terang adalah vertical louver sedangkan yang membuat ruangan paling gelap adalah eggcrate. Model shading devive yang membuat ruangan mempunyai pencahayaan paling seragam (uniformity ratio paling tinggi) adalah eggcrate sebaliknya vertical louver membuat ruangan mempunyai pencahayaan paling tidak seragam (uniformity ratio paling rendah). Shading device yang direkomendasikan adalah horizontal overhang dengan panjang 1.20 meter karena mempunyai nilai daylighting level rata-rata dan uniformity ratio cukup tinggi.
\end{abstract}

Kata kunci: pencahayaan alami, shading device, daylighting level, uniformity ratio

\section{PENDAHULUAN}

Alat pembayang matahari (shading device) pada jendela merupakan salah satu upaya untuk mengontrol atau mengurangi intensitas radiasi matahari yang masuk melalui jendela agar ruangan di dalamnya menjadi tidak terlalu panas sehingga beban pendinginan untuk $A C$ (Air Conditioning) juga berkurang (Kamal, 2010). Beberapa model shading device mampu mengurangi radiasi matahari langsung yang masuk dan secara efektif mendinginkan bangunan (Kamal, 2010). Pada penelitian sebelumnya dibuktikan bahwa dengan model shading device yang efisien mengurangi beban pendinginan untuk $A C$ sebesar $7 \%$ (Santamouris dkk, 1994).

Selain menghemat energi listrik untuk pendinginan, shading device juga menghemat energi listrik untuk lampu. Shading device mengoptimalkan pencahayaan alami dan mengurangi penggunaan lampu dari pagi sampai sore hari.

Fasad bangunan yang menghadap ke arah barat perlu perhatian khusus karena sinar matahari sore yang rendah menyebabkan sinar matahari langsung masuk ke dalam ruangan. Ruangan dengan jendela menghadap barat menjadi lebih panas pada sore hari jika shading device tidak berfungsi secara optimal melindungi jendela. Penelitian Puspitasari dan Syamsiyah, 2014 membuktikan bahwa horizontal overhang yang mempunyai panjang $25 \mathrm{~cm}$ pada sisi barat dan barat daya tidak optimal melindungi jendela yang mempunyai ukuran tinggi 1 meter dan lebar 0,5 meter terutama pada saat sore hari. (Puspitasari dan Syamsiyah, 2014:163). Shading device yang mampu melindungi jendela secara optimal jika horizontal overhang mempunyai panjang 
$180 \mathrm{~cm}$ yang dihitung berdasarkan pertimbangan sudut jatuh matahari (Puspitasari dan Syamsiyah, 2014:162). Jika tidak memungkinkan memasang shading device dengan panjang 180 $\mathrm{cm}$ maka digunakan 4 buah kisi beton yang membagi jendela menjadi 3 bagian secara vertikal dengan panjang kisi beton sebesar $40 \mathrm{~cm}$ (Puspitasari dan Syamsiyah, 2014:163).

Ruangan kelas pada umumnya digunakan dari jam 8 pagi sampai jam 5 sore. Pada jam-jam tersebut cahaya matahari masih bersinar maka pencahayaan alami perlu dioptimalkan pemanfaatannya agar penggunaan lampu berkurang sehingga menghemat listrik. Proses belajarmengajar berjalan lebih baik jika menggunakan pencahayaan alami (daylighting) karena cahaya alami yang masuk menimbulkan kesenangan dan efek daylighting sangat menarik (Ander, 1995:1).

Berdasarkan perumusan masalah di atas, perlu ditemukan model alat pembayang matahari (shading device) yang paling optimal untuk memenuhi kebutuhan pencahayaan alami di dalam ruangan kelas. Beberapa model shading device dieksperimen ke dalam Ecotect v5.20 agar diketahui nilai level pencahayaan alami (daylighting level) yang diukur dengan satuan lux.

\section{SAMPEL PENELITIAN}

Sampel penelitian yang digunakan adalah ruangan kelas 1 SMA yang berada di lantai 6, SMAK Penabur, Summarecon, Bekasi. Gedung Summarecon mempunyai alat pembayang matahari (shading device) eggcrate pada sisi selatan. Sampel penelitian tersebut pernah digunakan untuk penelitian sebelumnya yang membahas tentang pengaruh perubahan bentuk plafon terhadap waktu dengung (Sabtalistia, 2016).

Survei dilakukan pada tanggal 13 April 2016 mulai pukul 10.45 sampai pukul 11.00. Ruangan kelas mempunyai orientasi jendela pada arah selatan dan utara (Gambar 1 dan 2). Ruangan kelas berukuran 8,15 x 9,05 meter dengan ketinggian plafon 3 meter (Gambar 3). Jendela yang berada di dalam ruangan kelas maupun yang berada di koridor berada pada ketinggian $140 \mathrm{~cm}$ dari lantai.

Jendela sisi selatan berbatasan langsung dengan luar sedangkan jendela sisi utara berbatasan dengan koridor. Kondisi koridor cukup terang karena mempunyai jendela yang berbatasan dengan luar bangunan juga (Gambar 1 dan 2).

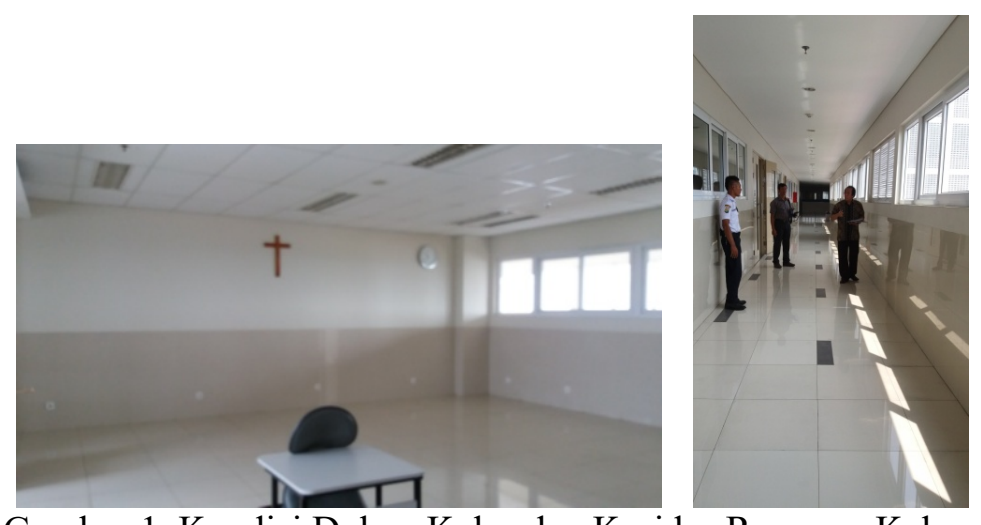

Gambar 1. Kondisi Dalam Kelas dan Koridor Ruangan Kelas (Survei, April 2016) 


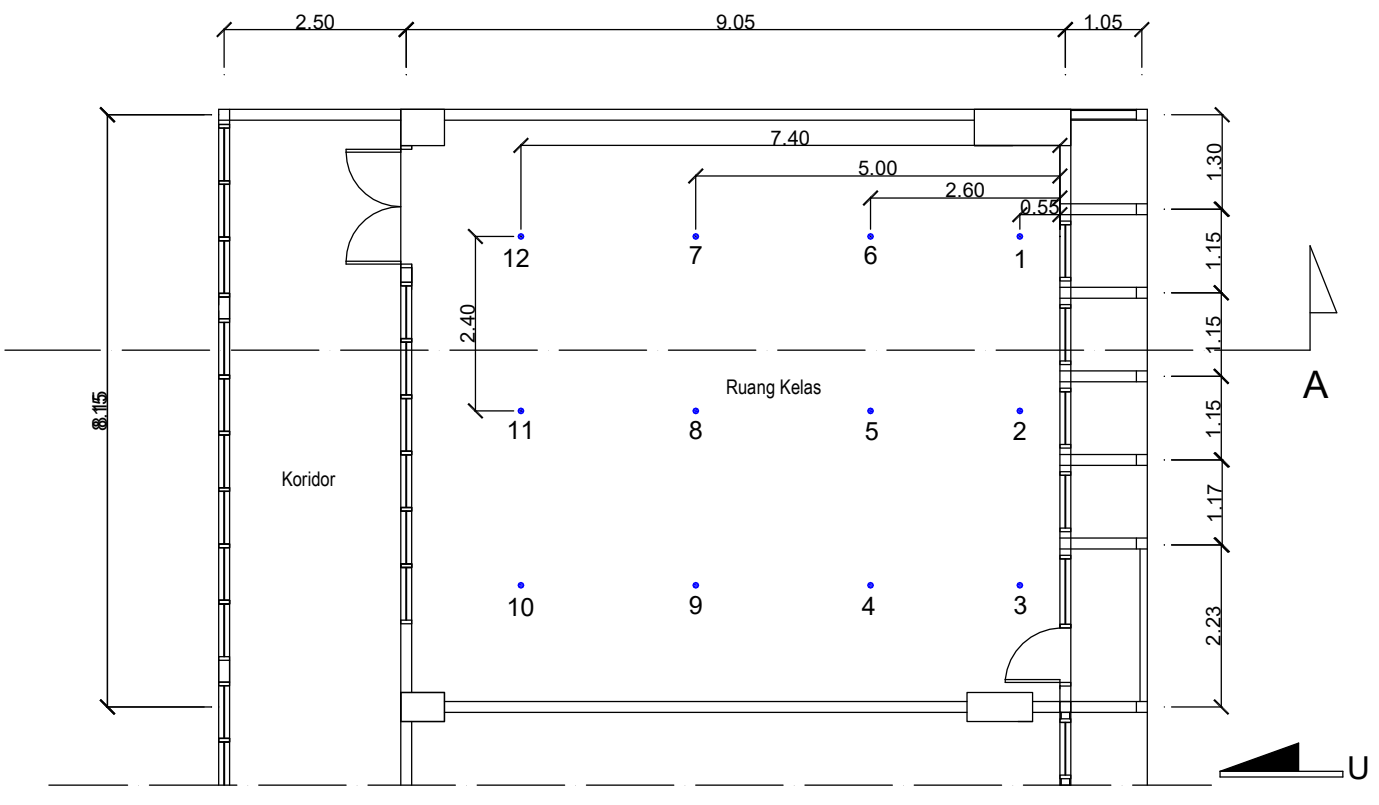

Gambar 2. Denah Ruangan Kelas

(Survei, April 2016)

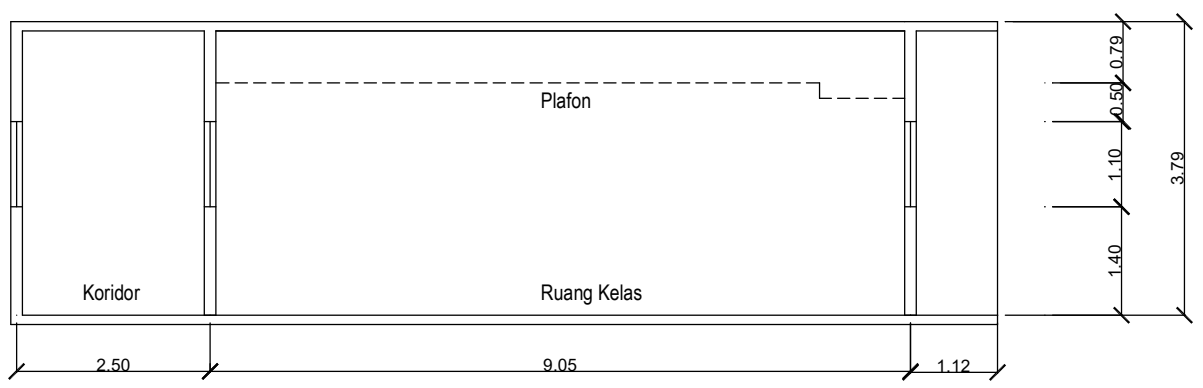

Gambar 3. Potongan A Ruangan Kelas

(Survei, April 2016)

Model eggcrate merupakan model shading device yang digunakan oleh ruangan kelas pada sisi selatan (kondisi yang ada di lapangan/eksisting). Model tersebut melindungi jendela dari empat sisi (Gambar 4).

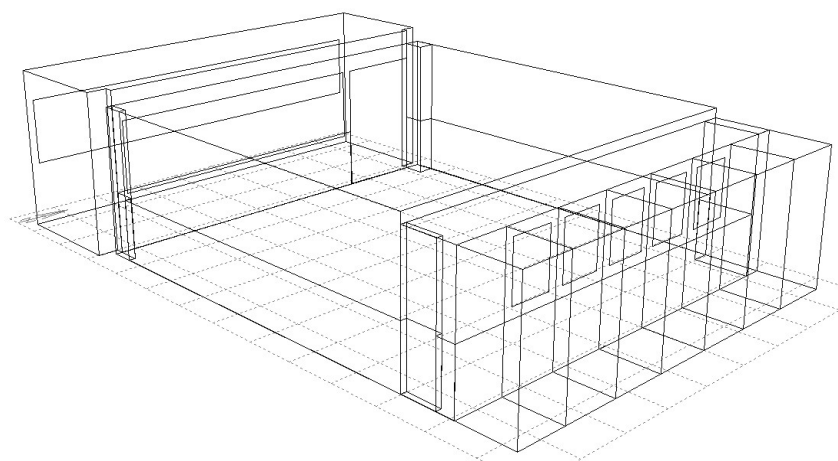

Gambar 4. Model Eggcrate pada Kondisi Eksisting

(Sumber: Modelling dengan Ecotect v5.20, 2016) 


\section{EKSPERIMEN DENGAN MENGGUNAKAN ECOTECT V5.20}

Metode yang digunakan adalah metode eksperimen. Beberapa strategi pengoptimalan pencahayaan alami dieksperimen untuk mengetahui perubahan daylighting level yang diukur dengan satuan lux dan tingkat keseragaman cahaya (uniformity ratio). Semakin tinggi daylighting level dalam suatu ruangan maka membuat ruangan menjadi semakin terang. Semakin tinggi tingkat keseragaman cahaya maka semakin baik pula kualitas pencahayaan alami karena selisih tingkat pencahayaan yang diukur dengan satuan $l u x$ tidak terlalu jauh antara nilai minimal dengan nilai rata-ratanya. Adapun rumus perhitungan uniformity ratio menurut Freewan dkk, 2009 adalah sebagai berikut:

Uniformity Ratio $=\frac{\text { minimal Illuminance }}{\text { average Illuminance }} \times 100$

dengan uniformity ratio $=$ tingkat keseragaman cahaya $(\%)$, minimal Illuminance $=$ level pencahayaan minimal (lux), average Illuminance = level pencahayaan rata-rata (lux).

Standard level pencahayaan tergantung aktivitas penghuni. Semakin detil aktivitas yang dikerjakan maka level pencahayaan yang dibutuhkan juga semakin tinggi. Pada tempat kegiatan belajar-mengajar (kelas), level pencahayaan yang dibutuhkan adalah 350 Lux (SNI 6197-2011).

Strategi pengoptimalan daylighting yang dieksperimen dengan menggunakan Ecotect v5.20 adalah dengan alat pembayangan eggcrate dengan panjang $1.12 \mathrm{~m}$ dan tinggi $3.79 \mathrm{~m}$ (kondisi eksisting), horizontal overhang dengan panjang $1.20 \mathrm{~m}$, horizontal louver dengan lebar $0.3 \mathrm{~m}$, vertical louver dengan lebar $0.3 \mathrm{~m}$ dan tinggi $1.10 \mathrm{~m}$, dan light shelf dengan panjang $1.65 \mathrm{~m}$ (Gambar 5 dan 6).

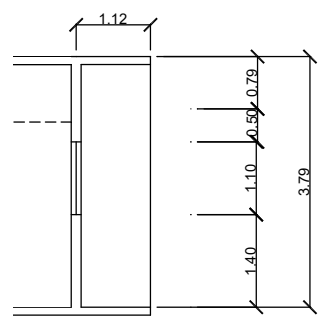

(a)

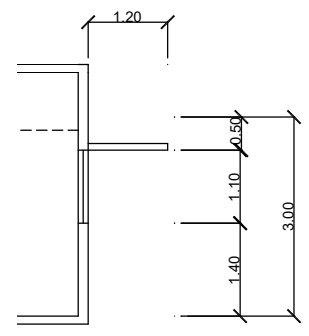

(b)

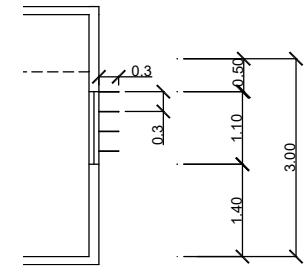

(c)

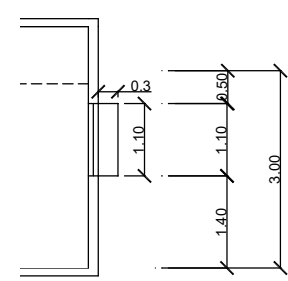

(d)

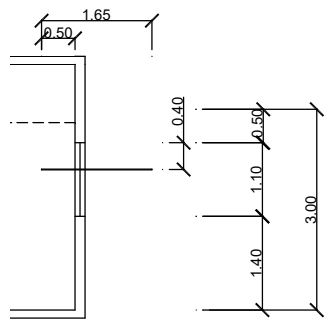

(e)

Gambar 5. Potongan A pada Beberapa Shading Device: (a) Eggcrate (Kondisi Eksisting), (b) Horizontal Overhang, (c) Horizontal Louver, (d) Vertical Louver, dan (e) Light Shelf 


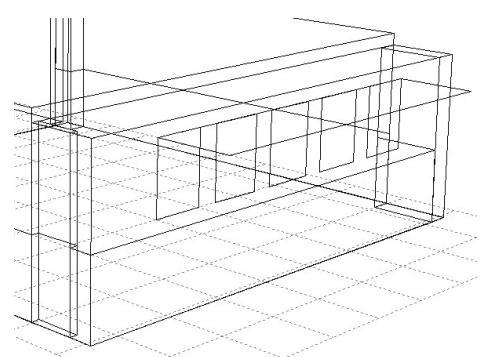

(a)

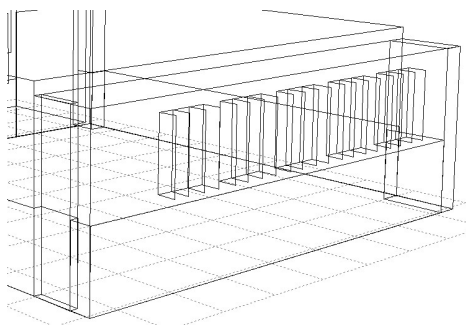

(c)

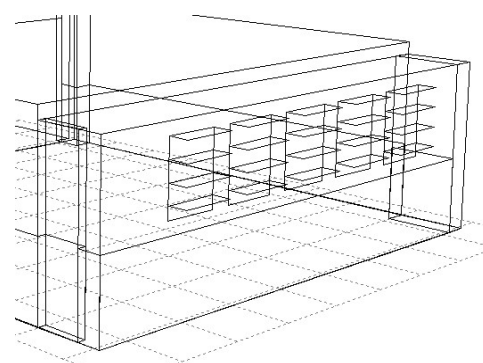

(b)

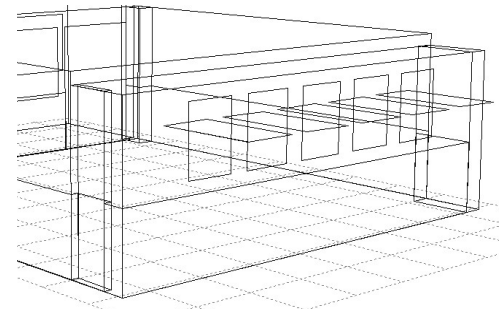

(d)

Gambar 6. Model Shading Device yang Dieksperimen dengan Ecotect v5.20:

(a) Horizontal Overhang, (b) Horizontal Louver, (c) Vertical Louver, dan

(d) Light Shelf

\section{ANALISA DAYLIGHTING LEVEL DAN UNIFORMITY RATIO}

Untuk mengetahui uniformity ratio perlu diperhitungkan 12 titik pengukuran daylighting level dengan ketinggian $80 \mathrm{~cm}$ dari permukaan lantai (Gambar 2 dan 7). Titik 1 sampai 3 mewakili area dengan jarak 0,55 meter dari jendela selatan, titik 4 sampai 6 mewakili area dengan jarak 2,6 meter dari jendela selatan, titik 7 sampai 9 mewakili area dengan jarak 5 meter dari jendela selatan, dan titik 10 sampai 12 mewakili area dengan jarak 7,4 meter dari jendela selatan (Gambar 2).

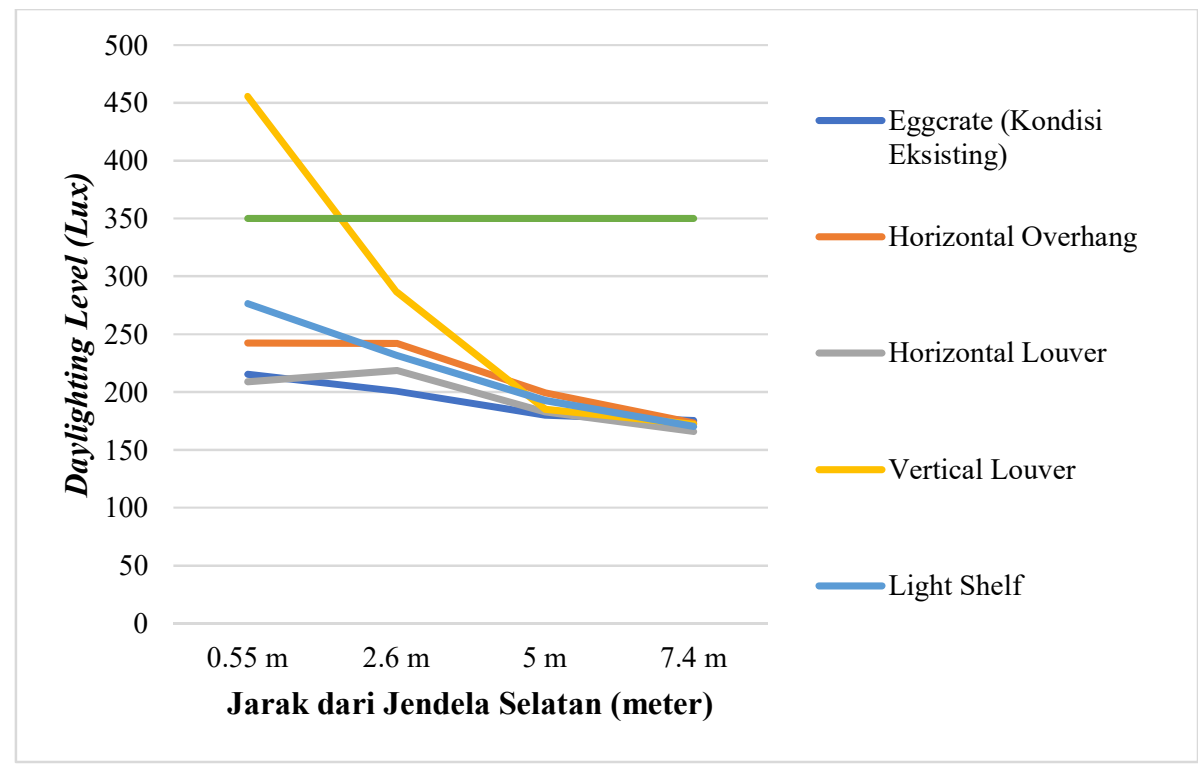

Gambar 7. Pengaruh Perubahan Jarak dari Jendela Selatan terhadap Daylighting Level pada Berbagai Model Shading Device (Diukur pada Ketinggian $80 \mathrm{~cm}$ dari Permukaan Lantai) 
Tingkat pencahayaan yang masuk dari jendela berubah sesuai dengan perubahan jauh dekatnya dengan jendela. Semakin jauh dari jendela maka berangsur-angsur menjadi semakin gelap begitu pula sebaliknya. Berdasarkan hasil eksperimen, vertical louver dengan lebar $0.3 \mathrm{~m}$ dan tinggi $1.10 \mathrm{~m}$ menyebabkan area yang di dekat jendela selatan menjadi terlalu terang (mencapai nilai rata-rata 455,31 lux) (Gambar 7). Sebaliknya eggcrate dengan panjang $1.12 \mathrm{~m}$ dan tinggi $3.79 \mathrm{~m}$ menyebabkan area yang di dekat jendela selatan menjadi tidak terlalu terang (mempunyai nilai rata-rata sebesar 215,50 lux).

Berdasarkan tingkat keseragaman cahaya (uniformity ratio), model shading device yang memberikan pencahayaan alami yang paling merata adalah eggcrate sedangkan yang paling tidak merata adalah vertical louver (Gambar 8). Model eggcrate mempunyai nilai uniformity ratio $89 \%$ sedangkan vertical louver hanya sebesar $62 \%$.

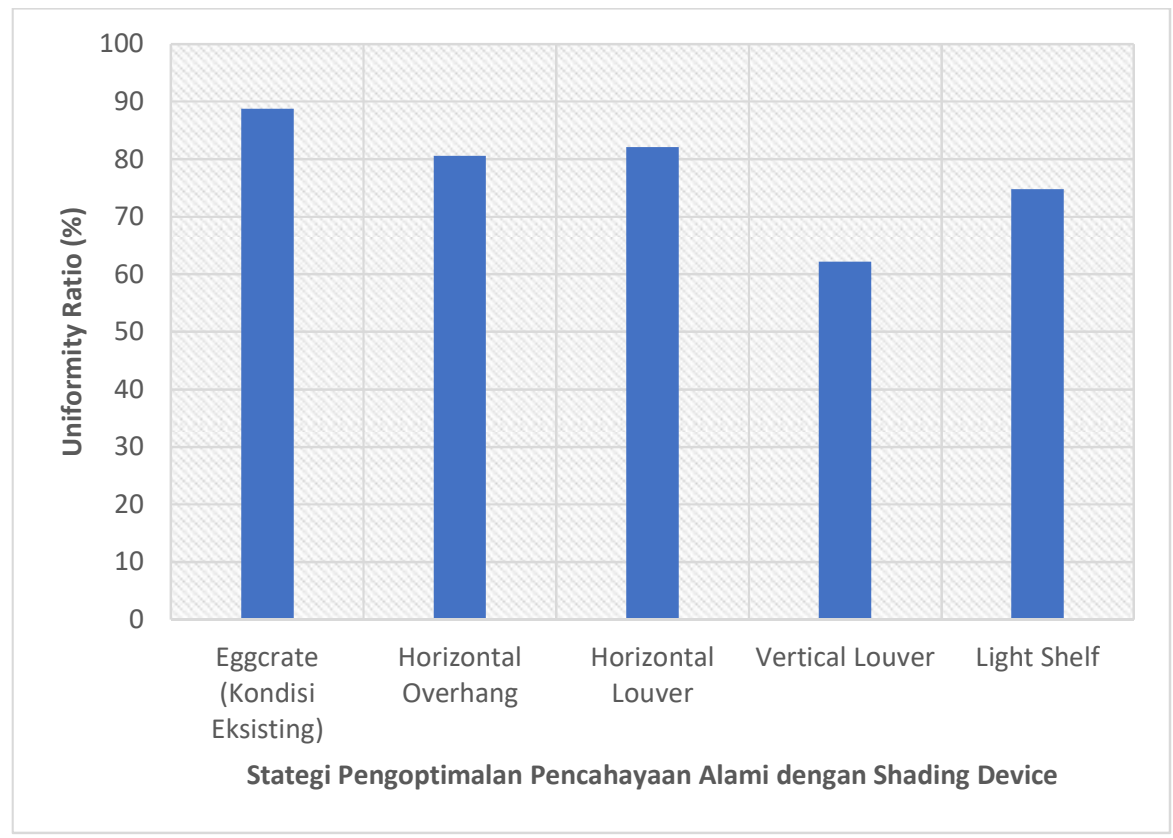

Gambar 8. Tingkat Keseragaman Cahaya (Uniformity Ratio) pada Berbagai Model Shading Device
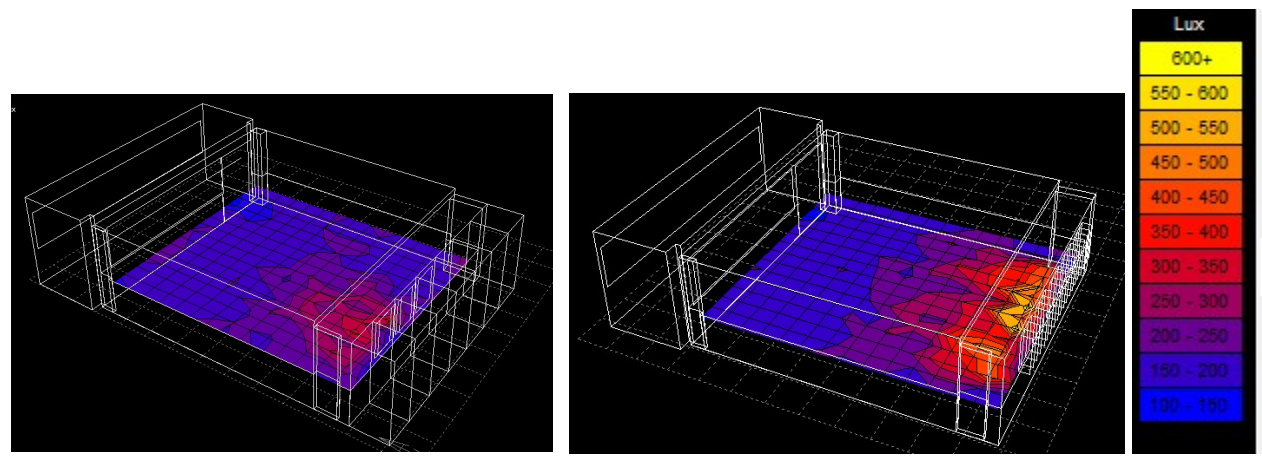

Gambar 9. Perbandingan Daylighting Level pada Eggcrate dengan Vertical Louver

(Sumber: Eksperimen dengan Ecotect v5.20) 
Gambar 9 menunjukkan bahwa area yang di dekat jendela selatan pada eggcrate lebih gelap daripada vertical louver. Oleh karena itu tingkat keseragaman cahaya pada eggcrate lebih tinggi daripada vertical louver karena tidak ada area yang terlalu terang dan terlalu gelap. Pada gambar potongan A (Gambar 10) terlihat lebih jelas bagaimana distribusi cahaya matahari yang masuk melalui jendela pada model eggcrate dan vertical louver. Pada area yang berada di dekat jendela selatan yang berbatasan dengan luar bangunan jauh lebih terang daripada area yang berada di dekat jendela utara yang berbatasan dengan koridor.
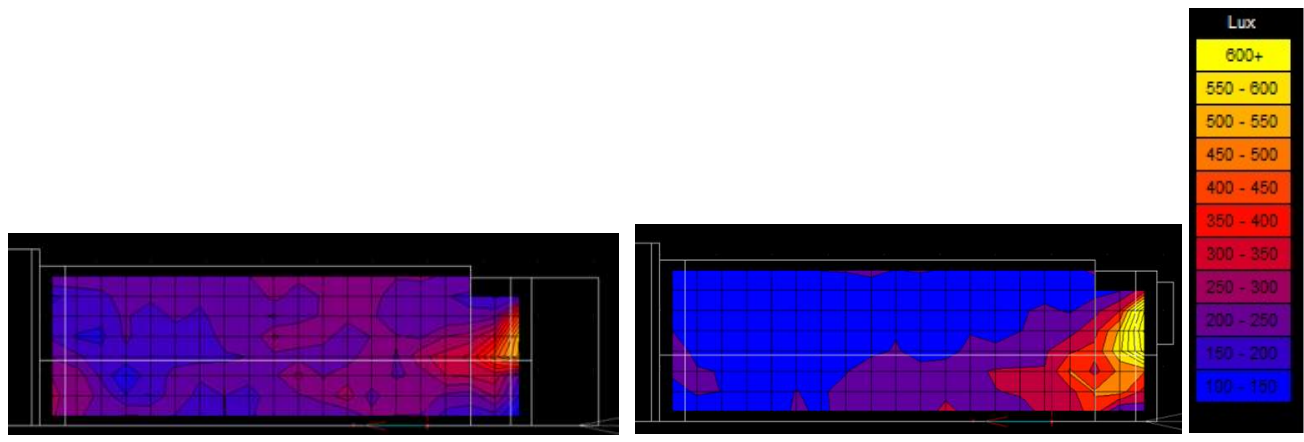

Gambar 10. Perbandingan Daylighting Level pada Eggcate dan Vertical Louver (Potongan A)

(Sumber: Eksperimen dengan Ecotect v5.20)
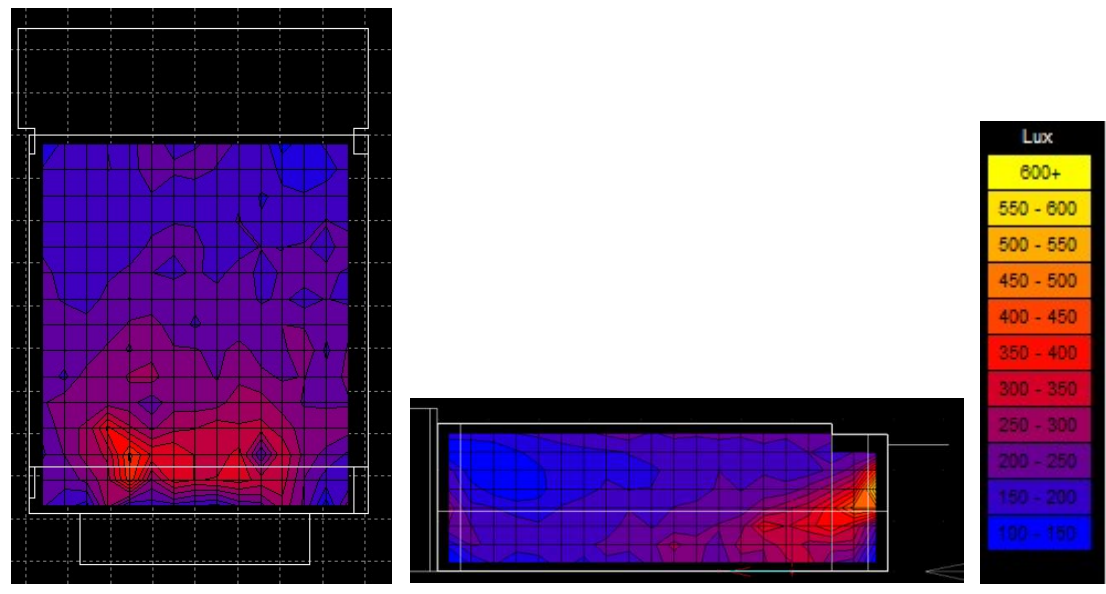

Gambar 11. Daylighting Level pada Ketinggian $80 \mathrm{~cm}$ dari Lantai (Tampak Atas) dan Daylighting Level (Potongan A) dengan Menggunakan Horizontal Overhang (Sumber: Eksperimen dengan Ecotect v5.20)

Model shading device yang direkomendasikan untuk digunakan adalah horizontal overhang dengan panjang $1.20 \mathrm{~m}$ karena mempunyai nilai daylighting level rata-rata sebesar 214,37 lux dan uniformity ratio sebesar 81\% (Gambar 11). 


\section{KESIMPULAN DAN SARAN}

Perubahan model shading device mempengaruhi nilai level pencahayaan alami (daylighting level) dan tingkat keseragaman cahaya (uniformity ratio). Berdasarkan hasil eksperimen dengan Ecotect v5.20, vertical louver paling mampu membuat ruangan kelas paling terang dan mendekati nilai 350 lux tetapi mempunyai tingkat keseragaman cahaya paling rendah. Model eggcrate menyebabkan ruangan menjadi paling gelap tetapi tingkat keseragaman cahayanya paling tinggi. Penggunaan horizontal overhang dengan panjang $1.20 \mathrm{~m}$ direkomendasikan karena mempunyai nilai daylighting level rata-rata mendekati vertical louver dan mempunyai nilai uniformity ratio mendekati eggcrate.

Untuk penelitian selanjutnya tidak hanya model shading device yang dieksperimen tetapi juga luasan jendela yang diubah ukurannya agar ditemukan model shading device dan ukuran jendela yang paling mampu mengoptimalkan pencahayaan alami di dalam ruangan kelas.

Ucapan Terima Kasih (Acknowledgement)

Ucapan terima kasih diberikan kepada beberapa pihak antara lain:

1. LPPI Universitas Tarumanagara sebagai pemberi dana penelitian

2. Ir. J.M Joko Priyono Santoso selaku Kepala Laboratorium Fisika Bangunan, Program Studi Sarjana Arsitektur, Universitas Tarumanagara

3. Kepala Sekolah dan Petugas SMAK Penabur Summarecon, Bekasi.

\section{REFERENSI}

Ander, G.D, AIA, (1995), Daylighting Performance and Design, John Wiley \& Sons, USA.

Freewan,A.A, Shao Li, dan Riffat Saffa. (2009). "Interactions between Louvers and Ceiling Geometry for Maximum Daylighting Performance". Renewable Energy., 34 (1), 223-232.

Kamal, M.A. (2010). "A Study on Shading of Buildings as a Preventive Measure for Passive Cooling and Energy Conservation in Buildings". International Journal of Civil \& Environmental Engineering IJCEE-IJENS., 10 (06), 19-22.

Puspitasari, M \& Syamsiyah, N.R. (2014). "Optimasi Shading Devices Rumah Tinggal (Studi Kasus: Perumahan Loh Agung VI Jaten Karanganyar)”. Sinektika., 14 (1), 158-164.

Sabtalistia, Y.A. (2016). "Pengaruh Bentuk Plafon terhadap Waktu Dengung (Reverberation Time)", Seminar Nasional Teknologi dan Sains (SNTS) II 2016, Universitas Tarumanagara, Jakarta 23-24 Agustus 2016, Hal 33-40.

Santamouris, M, Argiriou, A, Dascalaki, E, Balaras, C, dan Gaglia, A. (1994). "Energy Characteristics and Saving Potential in Office Building". Solar Energy., 52 (1), 59-66.

Standardisasi Nasional 6197-2011 tentang Konservasi Energi pada Sistem Pencahayaan. (2011). Badan Standardisasi Nasional, Jakarta. 